Ioana Schiau*

\title{
Women Gossip and Men Brag: Perceived Gender Differences in the Use of Humor by Romanian Older Women**
}

\begin{abstract}
The present study investigates perceived gender differences in the producion and social use of humor in the interpersonal communication of Romanian older women, aged 60 and above. The study is a qualitative investigation, based on semi-structured interviews. The aim was to understand the perceptions and motivations that women have when using humor in social interactions, and to explore the functions that humor serves in their day-to-day communication. A previous quantitative investigation found statistically significant gender differences between Romanian older men and women on a sense of humor scale, and suggested that the use of humor in interpersonal communication had stronger social benefits for women (Schiau, 2016a). Drawing on these findings, and keeping in mind other studies that discuss the different use of humor by men and women, this study aims to investigate specific gender differences in the production of humor, as perceived by the participants.
\end{abstract}

Keywords: gender, humor, older adults, women, Romania, interpersonal communication

\section{Introduction}

\section{Literature Review: Gender Differences in the use of Humor}

The field of interpersonal communication investigates the way humor functions in social contexts, its role in our communication strategies and its contribution to the success of our social interactions (Lynch, 2002). Ziv (2010) highlights that interpersonal humor "oils the wheels of communication" (p. 13), allowing us to build interpersonal relationships with minimum effort. The social and psychological advantages of humor, for all age and gender groups, are well documented by a growing body of studies. Morevoer, research suggests that the appreciation of humor can play a key role in maintaining an overall sense of wellbeing throughout the process of ageing (Damianakis \& Marziali, 2011), and a number of studies indicate that older people can make use of humor to more easily overcome the psychological effects of ageing (Berk 2001, Capps 2006a, Dziegielewski et al. 2004).

* National University of Political Studies and Public Administration, Bucharest, Romania. E-mail: ioana.schiau@comunicare.ro.

** This work is supported by a grant from the Social Sciences and Humanities Research Council of Canada to the Ageing, Communication, Technologies project (actproject.ca). 
The research literature on humor also discusses gender differences regarding the way men and women produce humor and can benefit, socially and psychologically, from its use. Greengross (2013) suggests that women, more often than men, use humor as a coping mechanism. Early studies on gender specific uses of humor found that women prefer to listen to and share amusing tales regarding everyday life (Crawford \& Gressley, 1991), as this creates a sense of communion and solidarity (Coates, 1996; Hay, 2000, 2002). Maltz and Borker (1983) also noted that the type of humor used by women creates social bonds and a feeling of solidarity. Conversely, Martin and colleagues (2003) highlighted the fact that men use more aggressive humor than women, while the type of humor used by men has been found by several studies to primarily serve the goal of status affirmation (Maltz \& Borker, 1983; Shuster, 2007). Kotthoff (2000) also found that, in informal conversations, women use more self-defeating humor, while men tell more jokes, use more humor directed at others and produce more humor on sexual topics. These findings are in line with studies discussing gender differences regarding interpersonal communication practices, in general. For example, a study by Kuhn and Villeval (2015) found women to be more focused on cooperation, while Gneezy and colleagues found that women were more likely to avoid competitive activities (Gneezy, Niederle, \& Rustichini, 2003; Niederle \& Vesterlund, 2007). Research by Dunbar and colleagues suggests that the conversations of women are directed in a manner that builds bonds and social networks, while the conversations of men are based primarily on "self-promotion" (Dunbar, Duncan, \& Marriott, 1997).

Other researchers discuss the different topics that men and women address in their use of humor. A series of early studies proposed not only that women cannot produce humor at all (see Lakoff, cited in Bing, 2007, p. 340), but also that women do not use, produce, or reproduce humor on topics regarding sex and sexuality. These presumptions were contradicted by studies that indicate women, especially in all-women groups, do appreciate sexual-themed humor, as long as it is not aggressive towards women (see Bing, 2007). Lundell (1993) maintains that it is unlikely for women to appreciate humor on sexual topics that have a hostile or aggressive component, a type of sexual-themed humor created by men, for men; he concludes that women appreciate humor on topics related to sex and sexuality as much as men do, when it is not hostile towards women. Dunbar and colleagues (1997) found that the conversations of women are often dominated by topics pertaining to family and children, while men do not approach these subjects as often. Against this background of thematic distinctions and similarities, it seemed relevant to investigate the opinions and perceptions of the participants in the present study in terms of topics for humor production.

Other studies have highlighted a gender difference in the way men and women self-evaluate their sense of humor. Ruch, Proyer and Weber (2010) found that, on the humor scale employed by their study, women evaluated their own sense of humor lower than men did, for all the age groups except for the oldest participants. This result was also obtained by Thorson and Powell on the Multidimensional Sense of Humor Scale (1993), and it was replicated by Schiau (2016a) on a group of Romanian older adults. One potential explanation for this finding replicated across the literature could be the widely spread social perception that men are funnier than women, an impression that is also reflected by research studies: for instance, a 2007 study by Shuster connected humor to higher levels of testosterone in the organism, which are characteristic of men. 


\section{The Present Study}

The present study departs from the research by Schiau (2016a) who investigated the use of humor in the interpersonal communication of Romanian older adults, aged 60 and over, in a quantitative approach, using the Multidimensional Sense of Humor Scale (Thorson \& Powell, 1993). Women in the sample obtained lower scores than men on three of the four subscales of the instrument (humor for negotiation, production and social use of humor, adaptive humor). This could equally be a matter of perception, as the data was self-reported, but it can also point to relevant gender-specific communication abilities and styles. The study also found that, for the women in the group, but not for the men, the production and social use of humor contributed to the reduction of the feeling of social loneliness. This could suggest that women's use of humor has social and emotional benefits, and the potential of managing the feeling of social loneliness - a mechanism that was not found in the case of men in the sample, despite their higher scores on the humor scale. This gender difference was not found in two other methodologically identical studies, one conducted on a group of English older adults aged 60 and older, and one with a group of Romanian students aged 18-30 (Schiau, 2016b), which could suggest both cultural and cohort differences. In order to explore these findings, and to better understand the connection between use of humor and the experience of loneliness for older women, a follow-up, qualitative, interview-based study was necessary. The aim was to explore the motivations of women aged 60 and older for using humor, their self-evaluation of the sense of humor, and perceived gender differences in the production of humor in interpersonal communication.

Consequently, the reseach questions of the present study regard perceived gender differences in the use of humor. Do older women identify and explain gender differences in the use of humor? Do women perceive humor-based communication as different in same-gender groups, compared to mixed-gender groups?

\section{Methodology}

\section{Method}

The present study was based on semi-structured interviews conducted during the month of February 2016. The interview guide contained questions about the production and social use of humor in interpersonal communication, the humor styles and topics used, and sense of humor and perceived gender differences in the use of humor.

The interviews primarily took place at the home of the participants. They were audio recorded, with the consent of the participants, and then transcribed to analyze the data. The interviewer also took notes about socio-demographic data and context information. Study participants came from varied socio-economic backgrounds in terms of income and level of education. However, most of the participants had benefitted from access to higher education.

\section{Participants}

A convenience sample of 11 Romanian older women, aged between 60 and 83, participated in the present exploratory study, giving their consent to be interviewed, after having understood the research objectives. 


\section{Results and Discussion}

Three primary perceived gender differences emerged in the data analysis: type of humor produced (canned or spontaneous/experience-based), topics for humor production, and communicational behaviours connected to humor production (gossip and bragging).

\section{Older Romanian Women and Experience-based Humor}

The women who participated in the study were asked to recall and describe a humorous interaction with another woman, or in a group of women. The findings were consistent with previous studies by Hay (2000), and suggested that, in interpersonal communication instances that make use of humor, women prefer to share stories and everyday events from their own lives, retold for the amusement of the other participants in the conversation. Hay suggests that sharing such humorous personal stories offers information that allows the source and the receiver to know each other better and increase solidarity.

"Women don't really tell jokes. They generally tell stories that are most often about themselves. Situations in which they were faced with a funny event, or something that someone else has told them. (...) I did this many times, listened to women's stories, events they were involved in, something happened to them, they were involved in a situation, happy or less happy, but the resolution of the story is that they came out of it all right." (woman, 70, higher education) One other implication of this finding is that women perceived themselves as using less canned humor, such as telling jokes, and relying more on spontaneous, experience-based humor.

"With another woman? Something silly, something trivial. Well, the moment the cat fell off the shelf into the dog's water bowl, which broke, and the kitchen was filled with water, and we laughed about it. Or... I don't know, we laugh continuously. When we laugh, we really laugh." (woman, 67, higher education)

"For everyone, even if you go to the market, something always happens to give you a reason to laugh, and when you meet other [women] you start to tell them, «hey, look at what soand-so did», or «listen to what someone said», and everyone starts to laugh and enjoy themselves, or there are also family problems, someone will say «listen to what my child said to me», it really is surprising how clever children are these days". (woman, 83, primary education)

One other finding regarding gender differences is the degree to which women reported discussing topics related to family and children, topics which previous studies found to be very present in the conversations of women, but less so in those of men (Dunbar et al., 1997). Gender roles have arguably changed in recent times, allowing us to speculate that, for younger adults, the topics of conversation and humor production could no longer be clearly deliniated. However, the finding seems relevant for the cohort under analysis, which clearly assigned gender roles.

\section{Humor Production: Women Gossip and Men Brag}

Women in the group reported that they use gossip in the interactions that they perceive as humorous. The topic of gossiping came up spontaneously during the interviews, when discussing the use of humor in same-gender groups.

One woman talked about her weekly meetings with a group of women who shared funny stories about their everyday life, but who also gossiped, an act that the participant described 
as indispensable to women. "It varies, sometimes we talk about human types, and, yes... it's normal to also make fun of others, but mostly... for example, for two years I went to the gym, but it was far away and we didn't do much there, I could have done those things at home, but I also went to socialize. I went twice a week, but every week we also went out for coffee afterwards. And that's where, of course... we talked about books we read or things like that... I am not one for gossip, but I am not obtuse either. We talked about things that happened, everyone has a funny story to tell. And a little gossip, it's not possible for women to not gossip." (woman, 70, higher education). Studies that deal with the phenomenon of gossip suggest that it plays an important role in the social group, contributing to its functionality and to group cohesion by creating social bonding (Dunbar, 2004). One study found that only less than 3$4 \%$ of conversations classified as gossip were malicious, but that gossip in the form of exchange of social information can take up to $65 \%$ of dialogue time (Dunbar et al., 1997).

While women declared to use gossip in their humorous conversations, their perception was that men use humor to brag. This is in line with Dunbar and colleageus (1997), who suggest that, generally, the conversations of men are based on self-promotion - a quality that we can speculate extends to their social production of humor, too. "Men, especially after they've had a drink, then they start telling, each more than the other, adventures from their lives, where they have been, things they did, each more boastful than the other, because bragging is a man's disease, women do it less, they are more modest, it is rarer to find a woman like that, but men like it: «Oh, I went there, I did that », or «I do this, I am so and so »." (woman, 83 , primary education). The women's perception of male-specific humor is consistent with studies that have found male humor to be based on status affirmation (Maltz \& Borker, 1983, Shuster, 2007). Studies about boastfulness in communication did indeed find gender differences, with women using a gentler way of self-praise, which is closer to simply sharing positive information, while the way men engage in bragging involves a more extreme way of presenting information and using more superlative terms, usually about one's own person (Miller, Cooke, Tsang, \& Morgan, 1992).

\section{Gender and Sexual-themed Humor}

The study participants were asked about the gender differences they perceive in the use of humor, in terms of preferred topics for humor production. The idea that men primarily create humor on topics regarding sex and sexuality emerged. The explanations that the women offered for this male-specific type of humor ranged from a crisis of masculinity in later life, to simply classifying men as vulgar.

"Yes, men, most of them, have more... worldly topics... There are men who are wellknown for being vulgar, for telling dirty jokes and what not..." (woman, 70, higher education)

"Men laugh a lot about sex-related topics, and women about men's flaws." (woman, 61, higher education)

"All these sexually themed jokes, I do not encourage them and I do not participate in them, especially not at my age. Men make such jokes, about potency, about this, about that, I think they are out of line. Men our age proably reach a crisis and then feel the need to make a joke about virility, stuff like that, which I think are, I don't know, frustrations..." (woman, 60, higher education).

This perceived difference is in accordance with findings that suggest men are more prone than women to use aggressive humor and to produce humor on sexual topics (Kotthoff, 2000; 
Martin et al., 2003). Moreover, we could speculate that this perceived gender difference is in line with the rather traditional gender roles that are still predominant in Romania (White, Vanc, \& Coman, 2011), which may lead to men being socially permitted to discuss members of the opposite sex in an aggressive and sexualizing manner. Lundell (1993) suggested that it is unlikely for women to appreciate such humor on sexual topics that is produced by men, for men, and has a hostile or aggressive component.

Studies that have investigated the use of humor in all-female groups challenge the idea that women do not appreciate sexual-themed humor, but rather value it just as much as men do, provided it is not aggressive and offensive to women (Bing, 2007). The fact that women do in fact engage in the production of humor on such topics is illustrated by the women who took part in the study. One participant, a former school teacher, said that "There are men who say dirty things; we also make filthy jokes, it's not a problem, in front of men and women. But if a man says «Look at her tits!», like students used to say in the school courtyard, with a certain tone, a certain facial expression ... Yes, usually men are more trivial than women, women are more delicate. Usually!" (woman, 67, higher education)

"Women do this very rarely, I have met women who tell such jokes with licentious terms, and some of them even tell them very well; I met a woman at a class meeting with former colleagues, we used to meet every five years, and one of our collagues had a wife who was very funny, she told jokes with extraordinary talent and everyone laughed, and she did use such terms... but she did not seem... as vulgar as men." (woman, 70, higher education).

Therefore, the idea emerged that women do, in fact, produce sexual-themed humor, but, in doing so, they perceive themselves as remaining "more delicate" and not "as vulgar as men".

\section{Conclusions and Study Limitations}

The study identified a series of perceived gender differences in the use of humor by a group of Romanian older women aged 60 and older, in terms of humor styles, topics and language, and use of canned versus experience-based humor.

The current study found evidence to suggest that women are more likely to use humor in a manner that creates solidarity, a sense of community and social bonds. They do that by sharing humorous personal anecdotes based on their own, everyday life experiences (rather than using canned humor in the form of jokes), and by exchanging social information in the form of gossip, which, studies maintain, has social bonding advantages. Conversely, women perceived male humor as a form of status assertion and self-promotion, likely using a style of aggressive, sexually-themed humor. These are instances of communicational behaviours that are not conducive to social bonding, but rather to competitiveness.

The women indicated that they do not reject humor about sex and sexuality per se, but rather were opposed to the men's approach to the topic, which they perceived as aggressive - a type of humor used by men, for men. The women confirmed that they also produced and appreciated "filthy" jokes, but they noted that, in doing so, they were not as vulgar as men.

There are some obvious limitations to this study. A limitation is the very topic under investigation, namely humor. Having a sense of humor has high social desirability and it is not unlikely that study participants have, to some degree, adjusted their answers in order to represent their use of humor in communication more favourably. Future studies investigating gender differences in the use of humor should take the next logical step and go beyond the 
study of perceptions, by analyzing actual episodes of humor-based communication, in samegender and mixed-gender groups.

Despite these limitations, the current study identified a series of relevant perceptions and behaviours in the interpersonal communication of Romanian older women. Investigating the perceptions of a group that has been largely neglected in mainstream research studies (older adults from Romania, and Eastern European populations generally) can lead to a better understanding of the functions of humor in older age.

\section{Bibliography}

Berk, R. A. 2001. The active ingredients in humor: psychophysiological benefits and risks for older adults. Educational Gerontology, 27, 3-4, 323-39. http://dx.doi.org/10.1080/036012701750195021.

Bing, J. (2007). Liberated jokes: Sexual humor in all-female groups. Humor-International Journal of Humor Research, 20(4), 337-366.

Capps, D. (2006). The Psychological Benefits of Humor. Pastoral Psychology, 54(5), 393-411.

Coates, J. (1996). Women Talk. Oxford: Blackwell Publishers.

Crawford, M., \& Gressley, D. (1991). Creativity, Caring, and Context: Women's and Men's Accounts of Humor Preferences and Practices. Psychology of Women Quarterly, 15(2), 217-231. http://doi.org/10.1111/ j.1471-6402.1991.tb00793.x.

Damianakis, T. \& Marziali, E. (2011). Community-dwelling older adults' contextual experiencing of humour. Ageing and Society, 31, 110-124. doi:10.1017/S0144686X10000759.

Dunbar, R. I. M., Duncan, N. D. C., \& Marriott, A. (1997). Human conversational behavior. Human Nature, 8, 231-246.

Dunbar, R. I. (2004). Gossip in evolutionary perspective. Review of general psychology, 8(2), 100.

Dziegielewski, S. F., Jacinto, G. A., Laudadio, A. and Legg-Rodriguez, L. 2004. Humor: an essential communication tool in therapy. International Journal of Mental Health, 32, 3, 90.

Greengross, G. (2013). Humor and aging - a mini-review. Gerontology, 59(5), 448/453. http://doi.org/ $10.1159 / 000351005$.

Gneezy, U., Niederle, M., \& Rustichini, A. (2003). Performance in competitive environments: Gender differences. QUARTERLY JOURNAL OF ECONOMICS-CAMBRIDGE MASSACHUSETTS-, 118(3), 1049-1074.

Hay, J. (2000). Functions of humor in the conversations of men and women. Journal of pragmatics, 32(6), 709-742.

Hay, J, 2002. Male cheerleaders and wanton women: humour among New Zealand friends. Te Reo (Journal of the Linguistic Society of New Zealand) 45, 3-36.

Kotthoff, H. (2000). Gender and joking: On the complexities of women's image politics in humorous narratives. Journal of Pragmatics 32, 55-80.

Kuhn, P., \& Villeval, M. C. (2015). Are Women More Attracted to Co-operation Than Men?. The Economic Journal, 125(582), 115-140.

Lundell, T. (1993). An experiential exploration of why men and women laugh. Humor 6 (3), 299-317.

Lynch, O. H. (2002). Humorous Communication: Finding a Place for Humor in Communication Research. Communication Theory, 12(4), 423-445. http://doi.org/10.1111/j.1468-2885.2002.tb00277.x.

Maltz, D. N., \& Borker, R. A. (1983). A cultural approach to male-female miscommunication. In J. J. Gumperz (Ed.), Language and social identity. Cambridge University Press. Retrieved from http://dx.doi.org/10.1017/ CBO9780511620836.013.

Martin, R. A., Puhlik-Doris, P., Larsen, G., Gray, J., \& Weir, K. (2003). Individual differences in uses of humor and their relation to psychological well-being: Development of the Humor Styles Questionnaire. Journal of research in per1sonality, 37(1), 48-75.

Miller, L. C., Cooke, L., Tsang, J., \& Morgan, F. (1992). Should I brag? Nature and impact of positive and boastful disclosures for women and men. Human Communication Research, 18(3), 364-399. 
Niederle, M., \& Vesterlund, L. (2007). Do Women Shy Away from Competition? Do Men Compete Too Much? The Quarterly Journal of Economics, 122(3), 1067-1101.

Ruch, W., Proyer, R., \& Weber, M. (2010). Humor as a character strength among the elderly Empirical findings on age-related changes and its contribution to satisfaction with life. Z. Gerontol. Geriatr., 43(1), 13-18. http://doi.org/10.1007/s00391-009-0090-0.

Schiau, I. (2016). Humor, Loneliness and Interpersonal Communication: A Quantitative Study of Romanian Older Adults. Romanian Journal of Communication and Public Relations, 18(1), 89-106. doi:http:// dx.doi.org/10.21018/rjepr.2016.1.204.

Schiau, I. (2016). Loneliness, Social Interactions and Sense of Humor. A Quantitative Study Comparing Romanian Students and Older Adults. Studies and Scientific Researches. Economic Edition, 0(23). Retrieved from http://sceco.ub.ro/index.php/SCECO/article/view/355/336.

Shuster, S. (2007). Sex, aggression, and humour: Responses to unicycling. British Medical Journal, 335(7633), 1320-1322.

Thorson, J. A., \& Powell, F. C. (1993). Development and validation of a Multidimensional Sense of Humor Scale. Journal of Clinical Psychology, 49(1).

White, C., Vanc, A., \& Coman, I. (2011). Corporate social responsibility in transitional countries: Public relations as a component of public diplomacy in Romania. International Journal of Strategic Communication, 5(4), 281-292.

Ziv, A. (2010). The social function of humor in interpersonal relationships. Society, 47(1), 11-18. 